\title{
The pathological effects of CCR2+ inflammatory monocytes are amplified by an IFNAR1-triggered chemokine feedback loop in highly pathogenic influenza infection
}

Sue-Jane Lin ${ }^{1,2,3^{*}}$, Ming Lo ${ }^{4}$, Rei-Lin Kuo ${ }^{1,2,3}$, Shin-Ru Shih ${ }^{1,2,3}$, David M Ojcius ${ }^{5}$, Jean Lu' ${ }^{6}$, Chien-Kuo Lee ${ }^{7}$, Hui-Chen Chen ${ }^{8}$, Meei Yun Lin ${ }^{1}$, Chuen-Miin Leu' ${ }^{9}$, Chia-Ni Lin ${ }^{3,10}$ and Ching-Hwa Tsai ${ }^{*}$

\begin{abstract}
Background: Highly pathogenic influenza viruses cause high levels of morbidity, including excessive infiltration of leukocytes into the lungs, high viral loads and a cytokine storm. However, the details of how these pathological features unfold in severe influenza infections remain unclear. Accumulation of Gr1 + CD11b + myeloid cells has been observed in highly pathogenic influenza infections but it is not clear how and why they accumulate in the severely inflamed lung. In this study, we selected this cell population as a target to investigate the extreme inflammatory response during severe influenza infection.
\end{abstract}

Results: We established H1N1 IAV-infected mouse models using three viruses of varying pathogenicity and noted the accumulation of a defined $\mathrm{Gr} 1+\mathrm{CD} 11 \mathrm{~b}+$ myeloid population correlating with the pathogenicity. Herein, we reported that CCR2+ inflammatory monocytes are the major cell compartments in this population. Of note, impaired clearance of the high pathogenicity virus prolonged IFN expression, leading to CCR2+ inflammatory monocytes amplifying their own recruitment via an interferon-a/ $\beta$ receptor 1 (IFNAR1)-triggered chemokine loop. Blockage of IFNAR1-triggered signaling or inhibition of viral replication by Oseltamivir significantly suppresses the expression of CCR2 ligands and reduced the influx of CCR2+ inflammatory monocytes. Furthermore, trafficking of CCR2+ inflammatory monocytes from the bone marrow to the lung was evidenced by a CCR2-dependent chemotaxis. Importantly, leukocyte infiltration, cytokine storm and expression of iNOS were significantly reduced in CCR2-/mice lacking infiltrating CCR2+ inflammatory monocytes, enhancing the survival of the infected mice.

Conclusions: Our results indicated that uncontrolled viral replication leads to excessive production of inflammatory innate immune responses by accumulating CCR2+ inflammatory monocytes, which contribute to the fatal outcomes of high pathogenicity virus infections.

Keywords: Influenza A virus, CCR2+ inflammatory monocytes, IFNAR1, CCL2, CCL7 and CCL12

\footnotetext{
* Correspondence: suejane.lin@mail.cgu.edu.tw; chtsai@ntu.edu.tw

${ }^{1}$ Research Center for Emerging Viral Infections, College of Medicine, Chang

Gung University, Tao-Yuan, Taiwan

${ }^{4}$ Graduate Institute of Microbiology, College of Medicine, National Taiwan

University, Taipei, Taiwan

Full list of author information is available at the end of the article
} 


\section{Background}

Influenza A virus (IAV) is a common human respiratory virus and causes seasonal epidemic and pandemic infections. In the past 100 years, pandemics of influenza have been caused by the IAV strains H1N1 (1918), H2N2 (1957), H3N2 (1968) and H1N1 (2009) [1,2]. These pandemic strains vary in their virulence and pathogenicy. Compared to the 1968 and 2009 pandemics, the 1957 pandemic featured intermediate pathogenicity, while the virus causing the 1918 pandemic was relatively highly pathogenic in the human population [2]. Currently we are threatened by sporadic infections by emerging avian IAVs, including highly pathogenic avian H5N1 and H7N9 viruses [1,3]. Two well known, highly pathogenic IAVs, 1918 H1N1 and avian H5N1 cause high levels of morbidity including excessive infiltration of neutrophils and monocytes into the lungs, high viral loads and hypercytokinemia, with significant increases of IL-1, IL-6, IL-8, TNF, CXCL10 and CCL2 in the patients' plasma [4-6]. Thus, cytokines and chemokines induced at high levels by IAV infections have become targets for the development of IAV therapy. However, the results of experiments using knock-out mice indicate that none of them alone determines highly pathogenic virus-induced lethality $[7,8]$. Thus, we used another approach to identify the immune cell types that are recruited during infection and contribute to the excessive inflammatory responses during highly pathogenic virus infection.

H1N1 IAV circulate continuously in the human population, and the three H1N1 strains selected for this study display low, intermediate and high virulence in mice as follows: (1) seasonal H1N1 A/Taiwan/141/02 (141; low virulence); (2) pandemic H1N1 A/Taiwan/126/2009 (swineorigin influenza virus, SOIV; intermediate virulence) and (3) mouse adapted H1N1 A/Puerto Rico/8/34 (PR8; high virulence). Using these mouse models, we demonstrated that rate of viral clearance and disease severity is correlated with the numbers of a defined Gr1 + CD11b + myeloid population in the lung. Until now, it is not clear how and why they accumulate in the severely inflamed lung. In this study, we selected this cell population as a target to investigate the extreme inflammatory response during severe IAV infection.

In this paper, we report that CCR2+ inflammatory monocytes are the major cell components in this defined $\mathrm{Gr} 1+$ $\mathrm{CD} 11 \mathrm{~b}+$ myeloid population. Multiple roles of CCR2+ inflammatory monocytes during viral infections have been reported: promoting host survival of West Nile virus-induced encephalitis and IAV and mouse hepatitis virus infections [9-12], stimulating anti-viral Th1 immunity in HSV-2 infection [13] and suppressing anti-viral CD8 T cell responses in mouse cytomegalovirus (MCMV) and persistent lymphocytic choriomeningitis virus (LCMV) infections $[14,15]$. These results indicate that CCR2+ inflammatory monocytes play a double edge sword in anti-viral responses and immunopathogenesis. Using established infection models with variable rates of viral clearance, which are accompanied by different levels of inflammatory infiltrates, we found that an amplified inflammatory chemokine feedback loop links the impaired clearance of highly pathogenic virus and a massive infiltration of CCR2+ inflammatory monocytes. So, we sought to investigate which cell types are responsible for the production of CCR2 ligands. Furthermore, we identified the inflammatory signals that are triggered by an impaired anti-viral response to induce expression of CCR2 ligands. Finally, the pathological effects of excessive accumulated CCR2+ inflammatory monocytes were explored during highly pathogenic IAV infection.

Overall, we provided a comprehensive study to address the detail mechanism why and how accumulated CCR2+ inflammatory monocytes involved in highly pathogenic IAV infections. Impaired clearance of virus led to spread of virus to newly arrived CCR2+ inflammatory monocytes and to sustain production of IFNAR1-induced CCR2 ligands, which attract BM-derived CCR2+ monocytes migrated to inflamed lung and amplify their own recruitment continuously through the IFNAR1-dependent chemokine feedback loop, resulting in an enhancement of CCR2+ inflammatory monocytes-mediated pathological effects.

\section{Methods \\ Mouse strains}

C57BL/6 and CCR2-/- mice were purchased from Jackson Laboratory (Bar Harbor, ME, USA). IFNAR1-/- mice were obtained from Dr. Chien-Kuo Lee (Graduate Institute of Immunology, National Taiwan University, Taipei, Taiwan). MyD88-/- mice were obtained from Hui-Chen Chen (Graduate Institute of Basic Medical Science, China Medical University, Taichung, Taiwan). Mice were maintained under specific pathogen free conditions in Chang Gung University. All animal experiments were performed according to the animal protocol approved by the Institutional Animal Care and User Committee of Chang Gung University and in accordance with the guidelines of Animal Care and Use of Laboratory Animals of the Taiwanese Council of Agriculture.

\section{Virus preparation and inoculation}

All segmented expression plasmids of IAV were kindly provided by Dr. Shin-Ru Shih of Research Center for Emerging Viral Infections, College of Medicine, Chang Gung University, Taiwan. Recombinant IAVs, seasonal 141, pandemic SOIV and mouse adapted PR8 were generated using a reverse genetics system, according to previous reports [16,17]. Briefly, $293 \mathrm{~T}$ cells were transfected by using $15 \mu \mathrm{l}$ Trans IT-LT1 (Mirus Bio LLC) with $1 \mu \mathrm{g}$ per each plasmid (pPolI-PB2, -PB1, -PA, -HA, -NP, -NA, 
-M, -NS of 141, SOIV or PR8). Recombinant IAVs were harvested and propagated in 10 day-old embryonated chicken eggs. Harvested viruses were aliquoted and stored at $-80^{\circ} \mathrm{C}$ until use. For IAV inoculation, mouse was infected intranasally with 200 PFU of virus.

\section{Plaque assays}

Lungs were harvested and grind tissue suspension were frozen in $600 \mu \mathrm{l}$ aliquots. Viral supernatant was thawed and then 10 folds serially diluted. MDCK cells were cultured at a density of $1 \times 10^{6}$ cells/well in a 6 well-plate. One hundred microliter of each serial dilution containing trypsin was added to $90 \%$ confluent of MDCK cells. After 1 hour incubation, each well was overlaid with a ratio of 1:1 mixture of $0.8 \%$ agarose and $2 \times$ serum free DMEM to wells. Two days later, the plaques were visualized by addition of $1 \%$ crystal violet and plaque forming unit (units/lung) was calculated.

\section{Preparation of lung leucocytes, mediastinal lymph node (MLN), bone marrow (BM) cells and PBMC}

Harvested lungs were homogenized using a metal mesh and the suspension was treated with type I collagenase (Invitrogen) per lung for 30 mins at $37^{\circ} \mathrm{C}$. Cells were recovered and washed once with complete PRMI medium containing 10\% FBS, $1 \mathrm{mM}$ glutamine, $100 \mathrm{U} / \mathrm{ml}$ of penicillin and $100 \mu \mathrm{g} / \mathrm{ml}$ of streptomycin. The pelvic and femoral bones were harvested and BM cells were flushed out with complete RPMI medium by insertion of a $1 \mathrm{ml}$ syringe with a $25 \mathrm{G}$ needle into one end of the bone. MLN cells were homogenized using glass slides with ground edges. Leukocytes were obtained from the lungs, peripheral blood, BM and MLN after RBC lysis buffer treatment.

\section{Cytokine antibody array and ELISA}

To obtain bronchoalveolar lavage fluid (BALF), airways were flushed three times with $0.5 \mathrm{ml}$ sterile PBS and centrifuged to remove infiltrating cells. Pooled BALFs were assayed using the $\mathrm{R} \& \mathrm{D}$ mouse cytokine arrays ( $\mathrm{R} \& \mathrm{D}$ Systems, Inc.) according to the manufacturer's instructions. CCL2, CCL7 and CCL12 proteins were measured in serum using ELISA kits (eBioscience) according to the manufacturer's instructions.

\section{Immunofluorescent surface and intracellular staining}

Two million cells were stained with fluorescently labeled mAbs, including Gr1, CD11b, Ly6C, Ly6G, CCR2 and CX3CR1 for $30 \mathrm{~min}$ at $4^{\circ} \mathrm{C}$. All Abs were purchased from BD Biosciences, except for CCR2 mAb (R \& D Systems). After staining, the cells were fixed with Cytofix (BD Biosciences) for $5 \mathrm{~min}$ at $4^{\circ} \mathrm{C}$. For intracellular staining, cells were stained with fluorescently labeled anti-Gr1, -CD11b and $-\mathrm{Ly} 6 \mathrm{C} \mathrm{mAbs}$ and then fixed with Cytofix/cytoperm
(BD Biosciences) for 20 mins at $4^{\circ} \mathrm{C}$. Fixed cells were further stained with FITC-labeled anti-IAV nucleoprotein (NP) $\mathrm{Ab}$ (Abcam) for another $30 \mathrm{~min}$ at $4^{\circ} \mathrm{C}$. Finally, the cells were washed and re-suspended in FACS buffer (PBS with $2 \%$ FBS) and analyzed by LSRII flow cytometry (BD Biosciences).

\section{Cell sorting and Wright stain}

Infiltrating leukocytes from the lungs were harvested and incubated with anti-Gr1, -CD11b and -Ly6G mAbs. Gr1 + CD11b+, Gr1-CD11b-, Gr1 + CD11b + Ly6G + (for granulocyte sorting) or Gr1 + CD11b + Ly6G- (for monocyte sorting) leukocytes were sorted by FACS Aria (BD Biosciences). For morphological evaluation of Gr1 + CD11b + cells, sorted cells were spun onto glass slides at $250 \mathrm{rpm}$ for 5 min using a Shandon Cytospin 3 Centrifuge (Global Medical Instrumentation Inc.) and stained with HemaTek stain Pak (Siemens Healthcare Diagnostic Inc.) using an automatic HemaTek hematology stainer (Bayer Healthcare, LLC.).

\section{RNA extraction, reverse transcription and quantitative polymerase chain reaction (RT-QPCR)}

Total RNA was extracted from isolated or sorted cells using TRIzol reagent (Invitrogen) according to the manufacturer's instructions. RNA was used to synthesize cDNA with Superscript III reverese transcriptase (Invitrogen). TaqMan ${ }^{\odot}$ Gene Expression Assays (Applied Biosystems) were performed to detect mouse CCL2, CCL7, CCL12, iNOS, IFN $\beta$ and GADPH mRNAs. Expression of the various genes was normalized with the GADPH level in each group. Relative gene expression was determined using $\Delta \Delta \mathrm{Ct}$ analysis.

\section{Western blotting}

Frozen lung tissues were lysed using lysis buffer $(100 \mathrm{mM}$ Tris, $250 \mathrm{mM} \mathrm{NaCl}, 0.5 \%$ sodium deoxycholate, $1 \mathrm{mM}$ PMSF and $0.5 \%$ NP40). Tissue lysates were resolved by electrophoresis in SDS-polyacrylamide gels and electrotransferred onto Hybond-P PVDF membranes (GE Healthcare). Milk blocked blots were incubated with anti-actin and -NP antibodies at $4^{\circ} \mathrm{C}$ overnight and then washed and incubated with horseradish peroxidase (HRP)-conjugated secondary antibodies (Jackson ImmunoResearch) at room temperature for $1 \mathrm{hr}$. The proteins were revealed using the Immobilon Western Chemiluminescent HRP Substrate (Millipore).

\section{Oseltamivir treatment}

PR8-infected mouse was treated with $50 \mathrm{mg}$ Oseltamivir daily according to a previous report [18].

\section{Treatment with anti-IFNAR1 blocking antibody}

Day 3 post-infected mice were anesthetized and then injected intranasally with either $50 \mu \mathrm{g}$ of IgG isotype control antibody (Abcam) or $50 \mu \mathrm{g}$ of anti-IFNAR1 


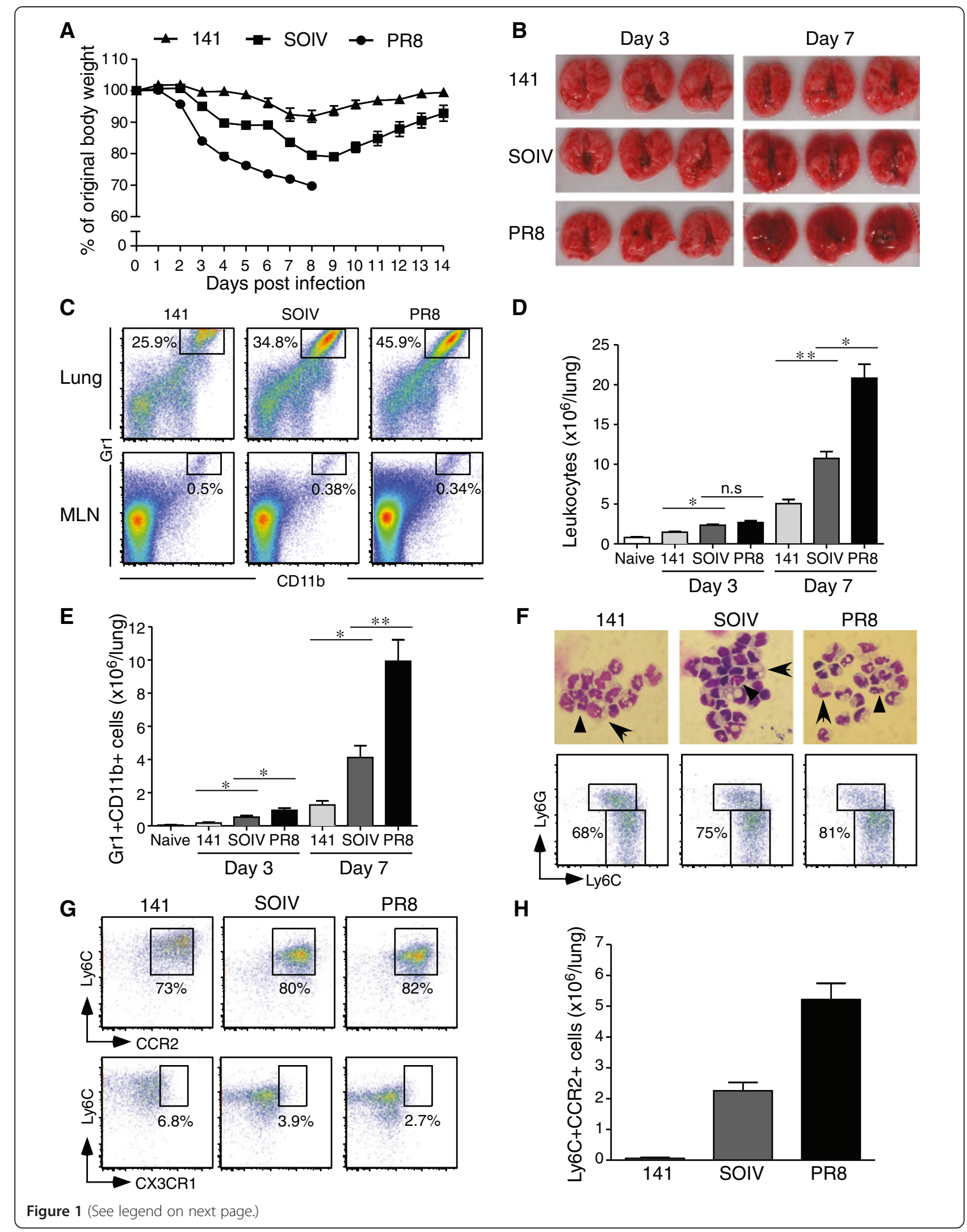


(See figure on previous page.)

Figure 1 Excessive accumulation of CCR2+ inflammatory monocytes in severe IAV infection. C57BL/6 mice were infected with 200 PFU of 141, SOIV or PR8 viruses. (A) Body weights were monitored daily until day 14 post-infection ( $n=6-8$ per group, mean \pm SEM). (B) Appearance of lung inflammation was photographed at days 3 and 7 post-infection ( $n=3$ per group). (C) Total leukocytes were stained with Abs against Gr1 and CD11b. The percentage of Gr1 + CD11b + myeloid cells was analyzed by flow cytometry. (D) Total leukocytes were harvested from the lungs at the time points indicated and counted by trypan blue exclusion. These data are a composite of four to seven independent experiments ( $n=3$ per group, mean \pm SEM; n.s: no significant difference; ${ }^{*} P<0.05$; $\left.{ }^{* *} \mathrm{P}<0.01\right)$. (E) Numbers of Gr1 + CD11b + myeloid cell of lung were shown. These data are a composite of four independent experiments ( $n=3$ per group, mean \pm SEM; ns: no significant difference; ${ }^{*}<<0.05$; $\left.{ }^{*} P<0.01\right)$. $(\mathbf{F}$, upper panel) $\mathrm{Gr} 1+\mathrm{CD} 11 \mathrm{~b}+$ cells were sorted from infiltrating leukocytes and then stained by Wright stain. The cell morphology was photographed under 1000x magnification using an Olympus microscope. Granulocytes are indicated by arrow heads and monocytes are indicated by arrows. (F, lower panel). The percentage of Ly6G-Ly6C high monocytes in the Gr1 +CD11b + gated population is shown. Dot plots are the representative result from three repeated experiments with three mice per group. (G) The percentage of CCR2+ inflammatory monocytes and CX3CR1 patrolling monocytes in Gr1 + CD11b + myeloid cells. (H) Numbers of $\mathrm{Ly}_{6} \mathrm{C}^{\text {high }} \mathrm{CCR} 2+$ inflammatory monocytes were shown at day 7 post-infection. This is a representative result from four repeated experiments with three mice per group.

antibody (eBioscience). After 3 days, infiltrating cells were counted and then stained with specific Abs against with Gr1, CD11b, Ly6G, Ly6C and CCR2.

\section{Adoptive transfer of BM enriched CCR2+ monocytes into mice}

BM cells from naïve B6 mice were harvested and monocytes were enriched by negative selection using an EasySep ${ }^{\text {tw }}$ Mouse Monocyte Enrichment Kit and EasySep ${ }^{\text {tw }}$ magnet system (STEMCELL Technologies Inc.). Enriched monocytes were suspended in PBS at a concentration of $2.0 \times$ $10^{7}$ cells $/ \mathrm{ml}$ and incubated with $5 \mu \mathrm{M}$ carboxyfluorescein diacetate succinimidyl ester (CFSE, Invitrogen) solution for $12 \mathrm{~min}$ at $37^{\circ} \mathrm{C}$. One million CFSE-labeled cells were adoptively transferred via the tail vein into naïve or virusinfected mice. After 2 days, leukocytes were harvested from the lungs and stained with anti-Ly6C and anti-CCR2 antibodies. Finally, CCR2 + CFSE + transferred monocytes were traced using flow cytometric analysis.

\section{Statistical analysis}

Statistical significance of the data was analyzed by Student's two-tailed $t$ test.

\section{Results}

Excessive accumulation of CCR2+ inflammatory monocytes in severe IAV infection

We observed varying levels of body weight change and lung inflammation in the infected mice and investigated which infiltrating cell type was associated with severe inflammation. As shown in Figure 1A, mice infected with the mild 141 strain lost 5\%-10\% of their original body weight, while the moderate SOIV strain caused 15\%-20\% original body weight loss. Notably, severe PR8 infection caused progressive weight loss and led to $100 \%$ mortality in the infected mice at day 7-10 post-infection. In these infections, lung inflammation was dramatically correlated with body weight loss at day 7 post-infection (Figure 1B). Furthermore, we demonstrated that a defined
$\mathrm{Gr} 1+\mathrm{CD} 11 \mathrm{~b}+$ myeloid population is preferentially recruited to the infected lung, but only few to MLN (Figure 1C). Of interest, the total numbers of infiltrating leukocytes and Gr1 + CD11b + cells were significantly associated with the severity of inflammation (Figure 1D and E). Gr1 $+\mathrm{CD} 11 \mathrm{~b}+$ cells are a heterogeneous cell population, so the true identity of major infiltrating cells should be further characterized using the Wright stain and by the expression of Ly6G and Ly6C on cell surface. Gr1 + $\mathrm{CD} 11 \mathrm{~b}+$ sorted cells consisted mostly of mononuclear cells containing abundant cytoplasmic vacuoles and few segmented granulocytes (Figure 1F, upper panel). Furthermore, $\mathrm{Gr} 1+\mathrm{CD} 11 \mathrm{~b}+$ cells are composed of appoximately 68-81\% monocytes (Ly6G-Ly6C ${ }^{\text {high }}$ ) and 19-32\% granulo-

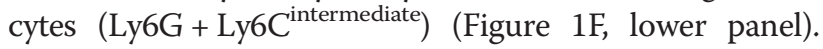
Using specific Abs against surface CCR2 and CX3CR1, we further demonstrated that the infiltrating monocytes in the lungs were Ly6C ${ }^{\text {high }}$ CCR2+ inflammatory monocytes but not Ly6C ${ }^{\text {low }}$ CX3CR1+ patrolling monocytes (Figure 1G). Importantly, the numbers of infiltrating CCR2+ inflammatory monocytes were highly associated with the severity of inflammation (Figure $1 \mathrm{H}$ ).

\section{Cytokine and chemokine profiling of BALFs}

To investigate the mechanism of extensive accumulation of CCR2+ inflammatory monocytes in severe inflammation, the cytokines and chemokines listed in Figure 2A were evaluated. According to the results of protein arrays, levels of G-CSF, CCL1, CCL2, CCL12, IL-10, CXCL9, IL16 and CCL5 were correlated with the severity of lung inflammation (Figure 2A). Notably, both CCL2 and CCL12 are ligands of CCR2, in addition to CCL7. So, we speculated that the aggressive recruitment of CCR2+ inflammatory monocytes is linked to expression of CCR2 ligands. In Figure 1C, we found that $\mathrm{Gr} 1+\mathrm{CD} 11 \mathrm{~b}+$ cells preferentially migrate to the lung but not to MLN. Therefore, we suggested that leukocytes infiltrating the lung may frequently induce CCR2 ligands to attract CCR2+ inflammatory monocytes. Indeed, all transcripts of CCR2 ligands 


\section{A}

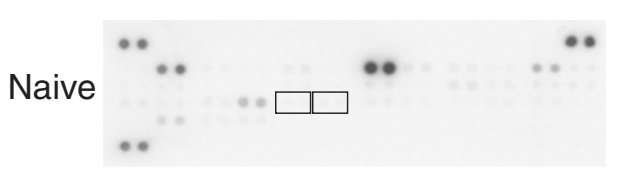

Day 3

141

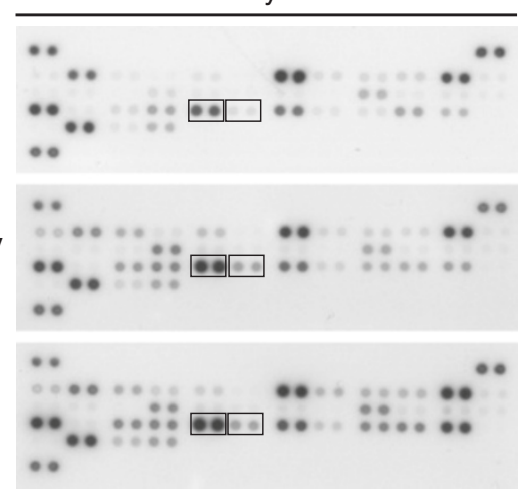

B

CCL 2

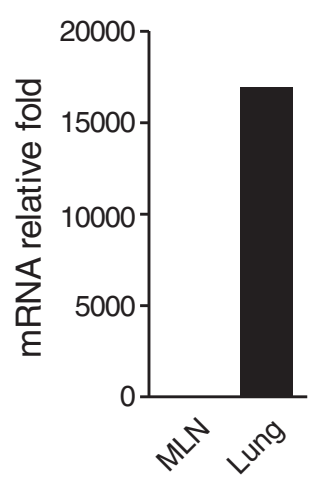

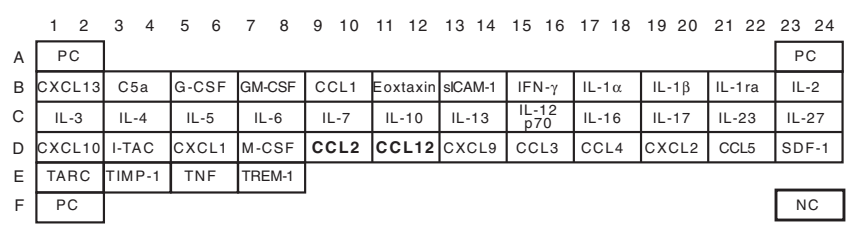

Day 7

141

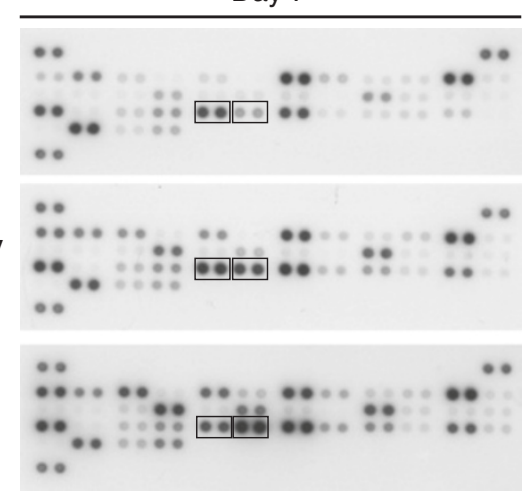

CCL 7

CCL 12

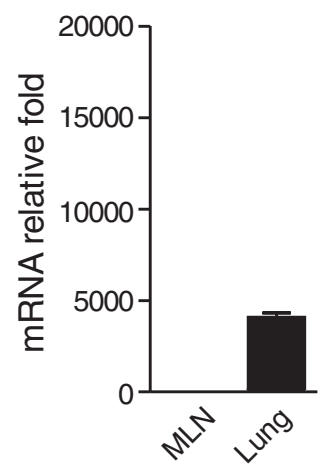

C
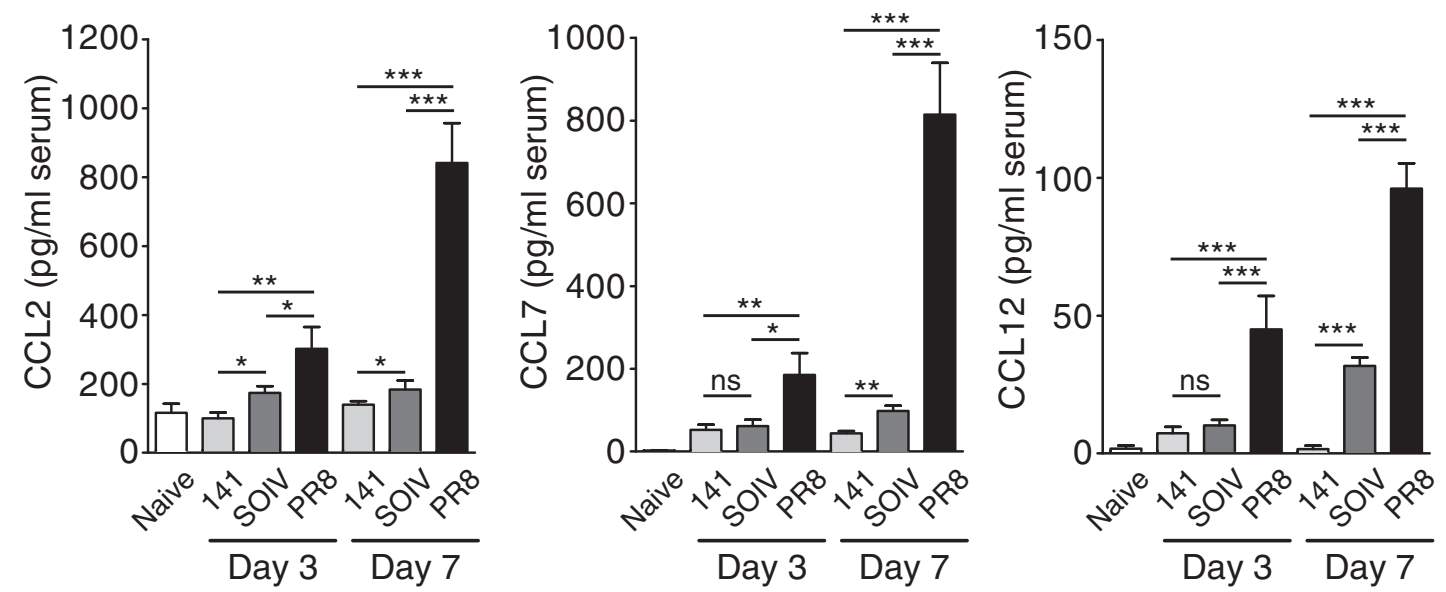

Figure 2 (See legend on next page.) 
(See figure on previous page.)

Figure 2 Expression of CCR2 ligands in BALF, MLN, lung and serum of infected mice. C57BL/6 mice were infected with 200 PFU of 141 , SOIV or PR8 viruses. BALF was harvested from naïve or virus-infected mice at days 3 and 7 post-infection ( $n=3-4$ mice per group). (A) Pooled BALFs were subjected to cytokine or ckemokine expression analysis using cytokine protein arrays. (B) Mice were infected with PR8 viruses. At day 7 postinfection, RNAs were harvested from isolated MLN and lung leukocytes. Relative expression of CCL2, CCL7 and CCL12 in total leukocytes from MLN and lung was measured by RT-QPCR. The mRNA relative folds were determined by normalizing the level of each group to the corresponding GAPDH level and then to total leukocytes from MLN (mean \pm SEM). Experiment ( $n=3$ mice per group) was performed twice and one representative is shown. (C) Sera were collected from naïve and virus-infected mice at days 3 and 7 post-infection. Concentrations of CCL2, CCL7 and CCL12 in the sera were measured by ELISA ( $n=6-11$ mice per group, mean \pm SEM; $n s$ : no significant difference; $\left.{ }^{*} P<0.05 ;{ }^{* *} P<0.01 ;{ }^{* *} P<0.001\right)$.

were over 4000 fold higher in the lung than in MLN (Figure 2B). In addition, the levels of CCR2 ligands in sera were clearly correlated with the numbers of infiltrating CCR2+ inflammatory monocytes (Figure $2 \mathrm{C}$ ). These results suggested that robust expression of CCR2 ligands may contribute to the aggressive recruitment of CCR2+ inflammatory monocytes into the lungs.

\section{Induction of CCR2 ligands by CCR2+ inflammatory monocytes}

We sought to determine whether the infiltrating Gr1 + $\mathrm{CD} 11 \mathrm{~b}+$ cells are possible producers of CCR2 ligands. To test this possibility, total infiltrating leukocytes were separated into Gr1 + CD11b + cells and Gr1-CD11b- cells using a cell sorter (Figure 3A). Compared to leukocytes in the lungs of naïve mice, infiltrating leukocytes harvested from virus-infected mice had tens- to thousands-fold induction of CCR2 ligands (Figure 3B). The relative fold induction of CCR2 ligands was similar between total leukocytes and Gr1 + CD11b + sorted cells, suggesting that $\mathrm{Gr} 1+\mathrm{CD} 11 \mathrm{~b}+$ cells are probably the main producers of CCR2 ligands. To confirm that CCR2+ inflammatory monocytes were producers of CCR2 ligands, granulocytes and monocytes were sorted from the Gr1 + CD11b + myeloid population (Figure 3C). As shown in Figure 3D, both cell types could express CCL2, CCL7 and CCL12, but more expression of these CCR2 ligands was seen in monocytes. Thus, our results suggested that infiltrating CCR2+ inflammatory monocytes act positively in a chemokine feedback loop to recruit more CCR2+ inflammatory monocytes.

\section{Induction of CCR2 ligands is dependent on IFNAR1-triggered signaling}

We next sought to determine which inflammatory signaling pathway was responsible for the induction of CCR2 ligands. Previous studies indicated that signaling pathways of MyD88 and type I IFN could modulate the recruitment of myeloid cells $[19,20]$. Therefore, MyD88-/and IFNAR1-/- mice were used in this study. Compared to infected WT and MyD88-/- mice, the expression of CCR2 ligands by $\mathrm{Gr} 1+\mathrm{CD} 11 \mathrm{~b}+$ cells was significantly reduced in infected IFNAR1-/- mice (Figure 4A). In addition, we found that the percentage of CCR2+ inflammatory monocytes was only reduced in IFNAR1-/- mice. In Figure 4B, CCR2+ inflammatory monocytes accounted for $81.8 \pm 1.1 \%$ of total leukocytes in infected WT mice and $84.5 \pm 4.5 \%$ in infected $M y D 88$ deficient mice; however, CCR2+ inflammatory monocytes accounted for only $39.8 \pm 0.35 \%$ in infected IFNAR1-/- mice. Thus, accumulation of CCR2+ inflammatory monocytes was suppressed when the IFNAR1-induced expression of CCR2 ligands was interrupted. Because aggressive recruitment of Gr1 + CD11b + cells was observed after day 3 post-infection (Figure 1E), we wondered whether intranasal treatment with an anti-IFNAR1 blocking antibody at day 3 post-infection could interrupt the influx of CCR2+ inflammatory monocytes. In Figure $4 \mathrm{C}$ and $\mathrm{D}$, the recruitment of CCR2+ inflammatory monocytes was reduced significantly in anti-IFNAR1 blocking antibody-treated mice, but not in isotype control-treated mice. Overall, these data implied that excessive recruitment of CCR2+ inflammatory monocytes contributes to continuous activation of IFNAR1-induced expression of CCR2 ligands.

\section{Impaired anti-viral responses prolong IFN $\beta$ expression}

Type I IFNs (IFN $\alpha$ and IFN $\beta$ ) are considerd to bind the heterodimeric complexes of IFNAR1 and IFNAR2. Recent study has shown that induction of CCL2 and CCL7 is triggered by the IFNAR1-IFN $\beta$ signaling in IFNAR2-/- mice [21]. In addition, we also observed differential expression of CCR2 ligands among Gr1 + CD11b + sorted cells in 141, SOIV and PR8 infections (Figure 3B). Therefore, we examined the expression levels of IFN $\beta$ in all infected mice. As expected, expression of IFN $\beta$ as detected only in the Gr1 + CD11b + sorted cells harvested from PR8infected mice at day 7 post-infection (Figure $5 \mathrm{~A}$ ). In addtion, both granulocytes and monocytes in $\mathrm{Gr} 1+\mathrm{CD} 11 \mathrm{~b}+$ population could express IFN $\beta$ (data not shown). Because detectable IFN $\beta$ production reflects activated viral replication, the anti-viral responses of the host were examined by measuring virus titers and detecting influenza NP expression in the infected lung. As shown in Figure $5 \mathrm{~B}$ and $\mathrm{C}$, 141-infected mice completely eliminated the virus at day 7. SOIV-infected mice still showed weak expression 


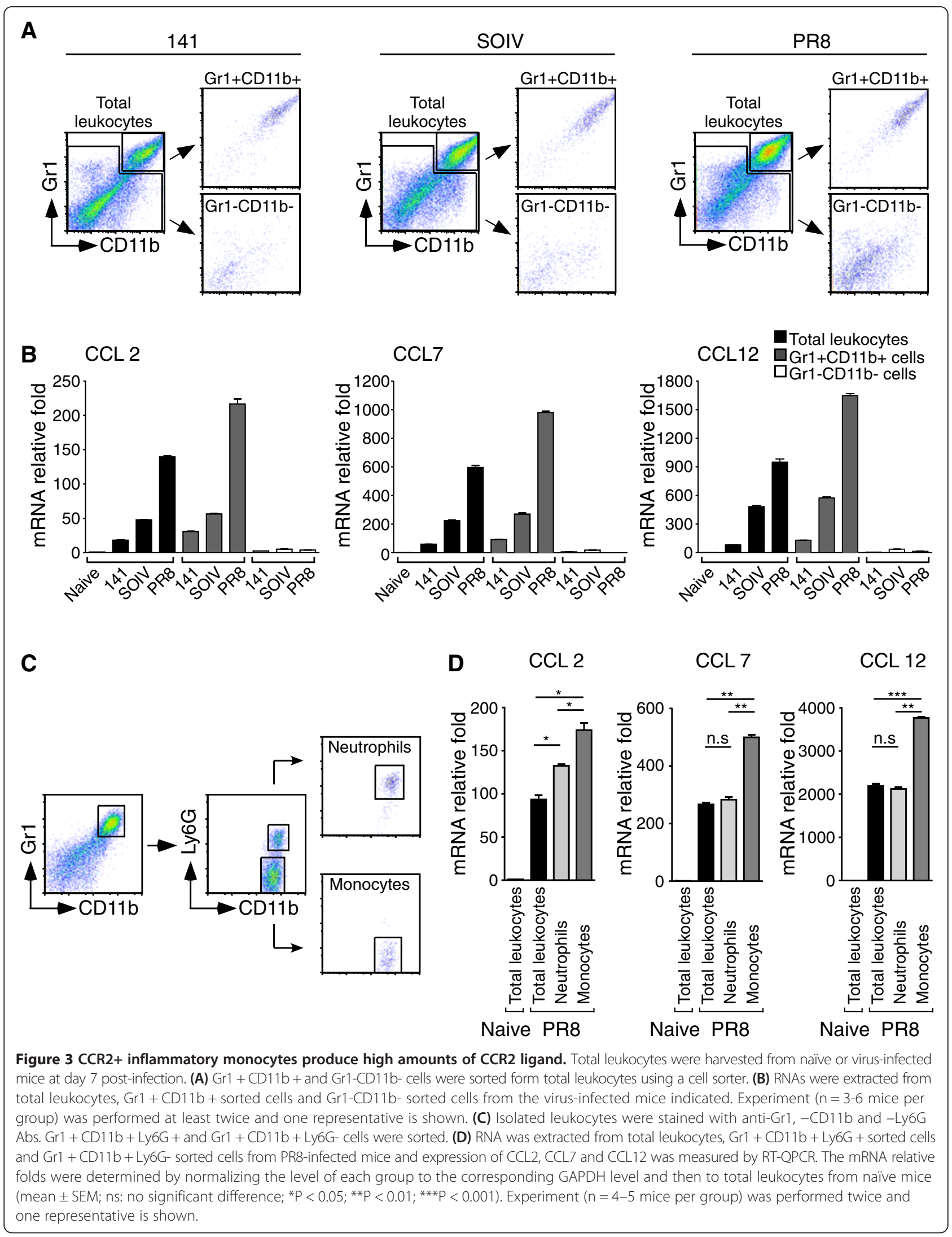




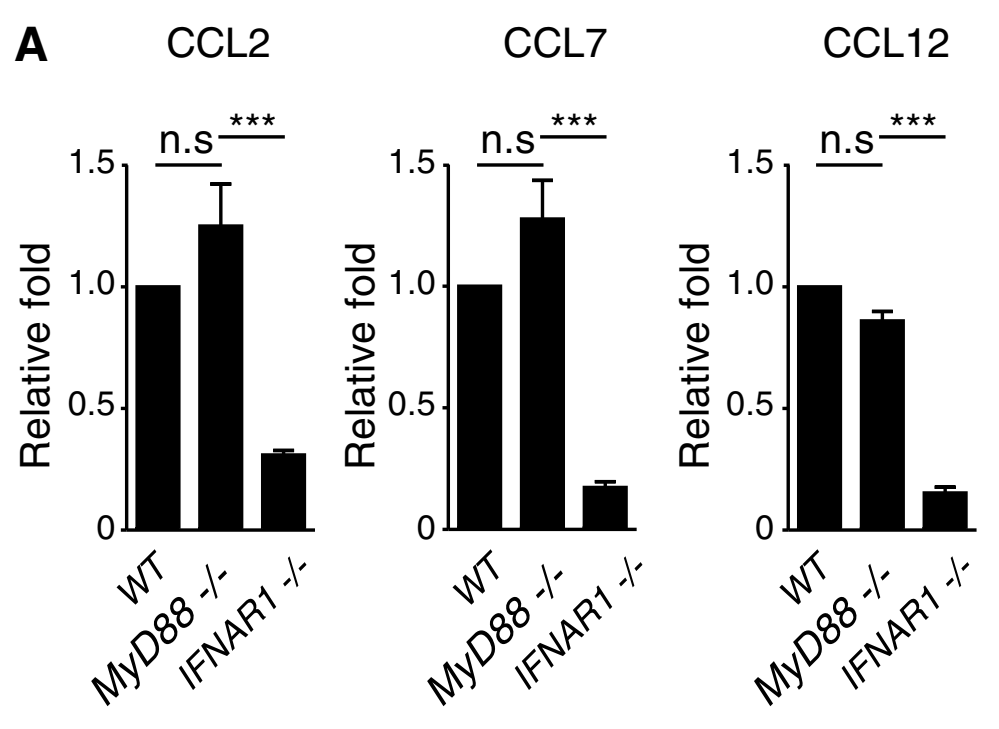

B

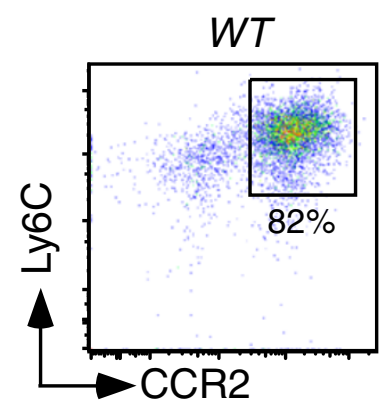

IFNAR1-/-

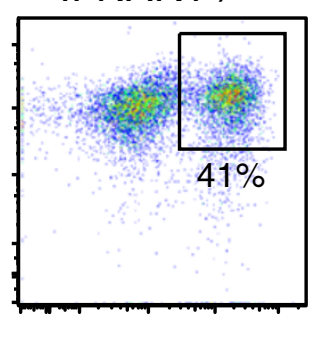

C
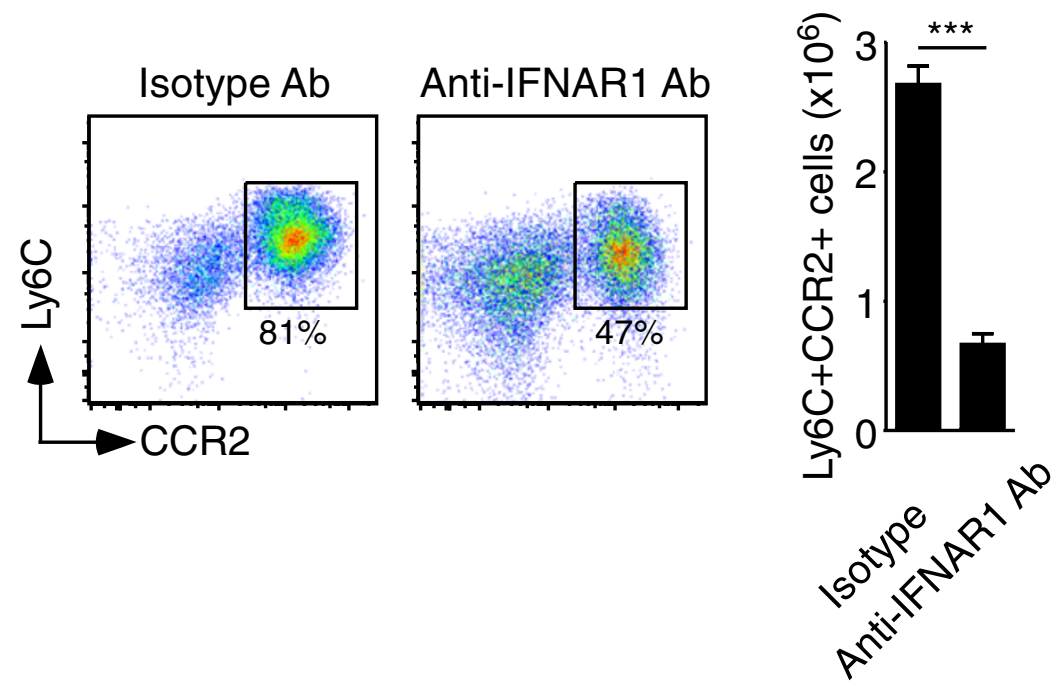


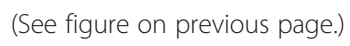

of NP at day 7 and the host completely cleared the virus at day 8 post-infection. Of note, PR8-infected lungs still showed strong NP expression and viral replication at day 7-8 post-infection. These data suggested that the duration of IFN $\beta$ production is a function of the rate of viral clearance. Next, we sought to explore why Gr1 + $\mathrm{CD} 11 \mathrm{~b}+$ cells produce abundant IFN $\beta$ in PR8-infected mice in the late phase of infection. We hypothesized that recruited $\mathrm{CCR} 2+$ inflammatory monocytes are infected by the PR8 virus, resulting in amplified production of IFN $\beta$. Indeed, expression of influenza NP was detected in CCR2+ inflammatory monocytes in PR8-infected mice (Figure 5D). Thus, our results suggested that impaired clearance of PR8 virus prolonged expression of IFN $\beta$, which led to infected CCR2+ inflammatory monocytes amplifying their own recruitment by an IFNAR1-triggered chemokine feedback loop. To determine whether high viral loads are potent inducers for CCR2+ monocyte infiltration, an anti-viral drug, Oseltamivir, was used to suppress virus replication in infected mice. In Figure 5E, body weight loss was attenuated when infected mice received Oseltamivir treatment, demonstrating the efficacy of Oseltamivir. Influx of CCR2+ inflammatory monocytes was dramatically reduced in Oseltamivir-treated mice, compared to PBS-treated mice (Figure 5F). Taken together, our results supported the concept that continuous recruitment of CCR2+ inflammatory monocytes by the IFNAR1-triggered chemokine feedback loop is attributable to the extended duration of IFN $\beta$ expression in the late phase of infection.

\section{The balance of CCR2+ inflammatory monocytes between the $\mathrm{BM}$ and lungs}

We next examined the source of infiltrating CCR2+ inflammatory monocytes in the host. In general, CCR2+ inflammatory monocytes are generated from the BM and migrate rapidly to inflamed sites following pathogen invasion [22]. Therefore, we first checked the proportions of Gr1 + CD11b + cells and CCR2+ inflammatory monocytes in the PBMC and BM during infection. As shown in Figure 6A-D, the proportion of $\mathrm{Gr} 1+\mathrm{CD} 11 \mathrm{~b}+\mathrm{cells}$ and CCR2+ inflammatory monocytes in the PBMC was positively correlated with disease severity. In contrast, the proportion of CCR2+ monocytes in the BM was inversely correlated with the severity of inflammation (Figure 6E). In Figure 6F, total CCR2+ monocytes were significantly decreased in the BM of PR8-infected mice, compared to those in 141- and SOIV-infected mice. These results implied that CCR2+ monocytes are rapidly recruited from the BM to the infected lung and mobilization of these cells is possibly dependent on the expression of CCR2 ligands. To demonstrate CCR2mediated trafficking of inflammatory monocytes to the lungs, BM-enriched CCR2+ monocytes were isolated from naïve mice, labeled with CFSE, and then adoptively transferred to naïve, 141-, SOIV- or PR8-infected mice. After 2 days, transferred CCR2+ inflammatory monocytes were traced by the CCR $2+$ CFSE + signals on the cells (Figure 6G). In Figure 6H, more transferred CCR2 + CFSE + monocytes were found in PR8-infected lungs than in those 141- and SOIV-infected lungs. CCR2-I- mice were used to confirm that influx of CCR2+ inflammatory monocytes was dependent on CCR2-triggered chemotaxis. In Figure 6I, the proportion of $\mathrm{Gr} 1+\mathrm{CD} 11 \mathrm{~b}+$ cells was significantly decreased in infected CCR2-/- mice, compared to WT mice. In Figure 6J, only few CCR2+ inflammatory monocytes were detected in the blood and lungs of infected CCR2-/- mice, suggesting the importance of CCR2-driven monocytes localization within the infected lung.

\section{Pathological effects of CCR2+ inflammatory monocytes upon IAV infection}

A previous study showed that monocytes are retained in the BM when they lack CCR2 expression [23]. To investigate the biological consequences of an excessive accumulation of CCR2+ inflammatory monocytes in the lungs, CCR2-/- mice were used to examine leukocyte infiltration, cytokine storm, expression of iNOS and the survival rate after a lethal dose challenge of PR8 virus. In the absence of infiltrating CCR2+ inflammatory monocytes, total leukocytes in the lung and expression of CCL1, sICAM-1, IFN $\gamma$, IL-1ra, IL-16, M-CSF, CCL2, CCL12 and CXCL9 in BALF were decreased, suggesting that CCR2+ inflammatory monocytes contribute to the expression of these molecules (Figure 7A and B). Consistent with the results from 


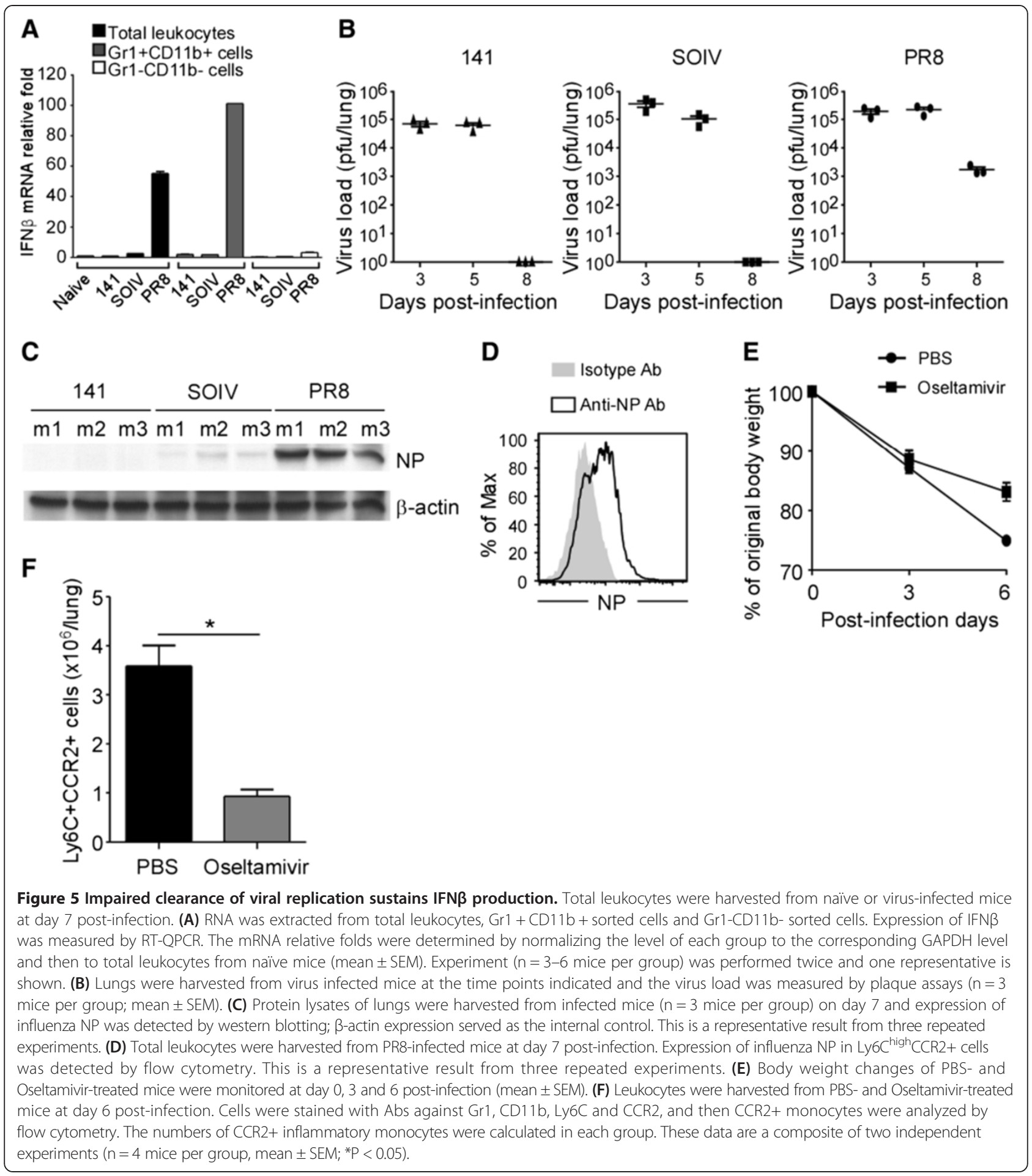

cytokine arrays, expression of CCR2 ligands was also significantly decreased in the infiltrating leukocytes of CCR2-/- mice, compared to WT mice (Figure 7C). A previous report has shown that iNOS is induced in activated myeloid cells and significantly involved in the development of IAV-induced pneumonitis [24]. As shown in Figure 7D, Gr1 $+\mathrm{CD} 11 \mathrm{~b}+$ cells were the predominant producers of iNOS. Interestingly, expression of iNOS was correlated with the severity of inflammation. To demonstrate further the importance of CCR2+ inflammatory monocytes-mediated immunopathological effects, expression of iNOS and the survival rate were compared 


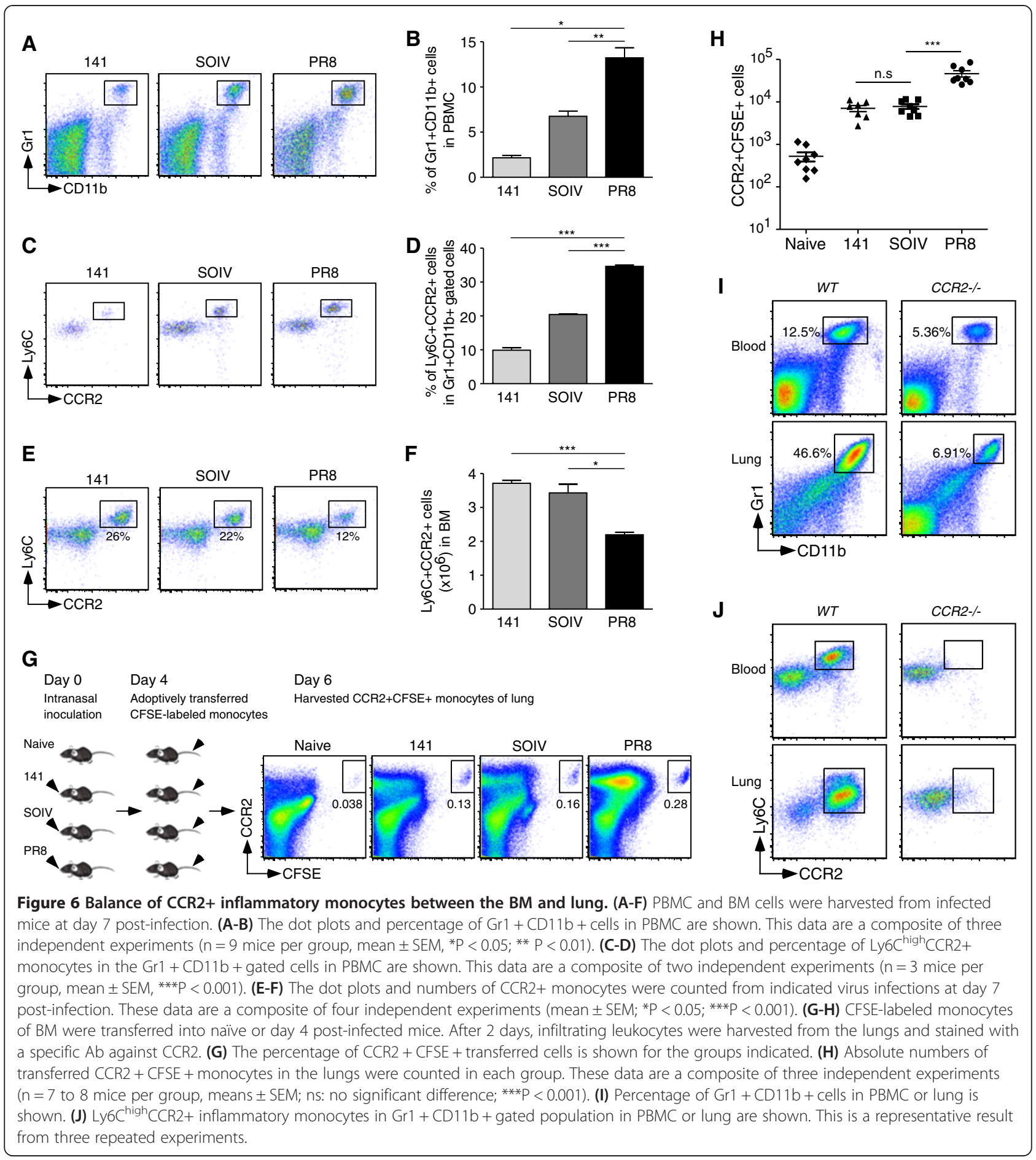

in PR8-infected WT and CCR2-/- mice. Expression of iNOS transcripts was dramatically reduced in infected CCR2-/- mice, (Figure 7E). Finally, 38.5\% of infected CCR2-/- mice, but none of the WT mice, survived a lethal dose challenge of PR8 virus (Figure 7F). Thus, infiltrating CCR2+ inflammatory monocytes play a pivotal role in highly virulent IAV infection-mediated pathological effects.

\section{Discussion}

IAV not only infect pulmonary epithelial cells, endothelial cells and resident alveolar macrophages but also infiltrating granulocytes, monocytes and dendritic cells $[18,25]$. Furthermore, infected leukocytes are the main contributors to aggressive production of inflammatory innate immune responses. Before entering the inflamed lung, these uninfected infiltrates are already primed with 
A

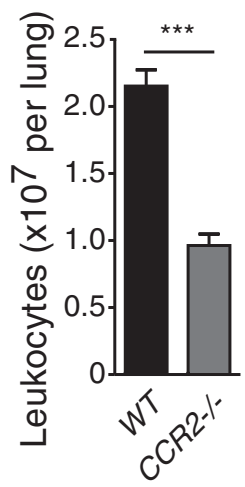

B
WT BALF

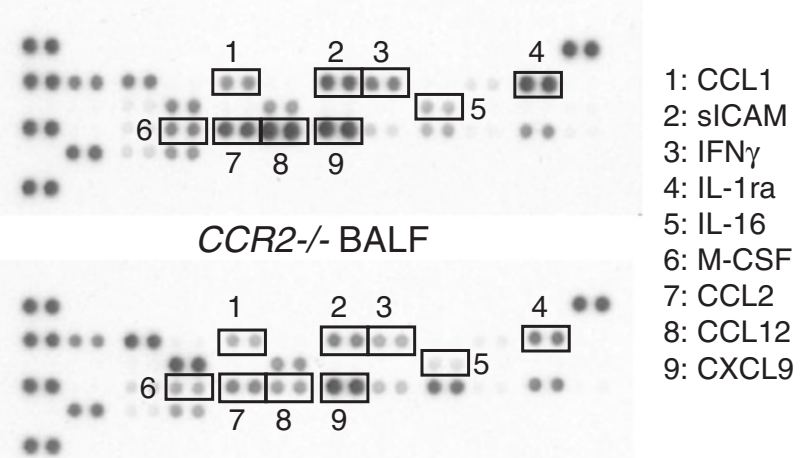

C
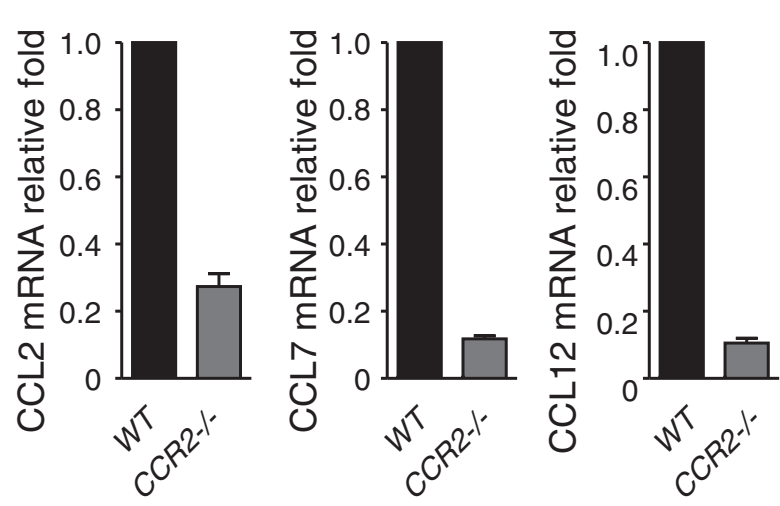

E

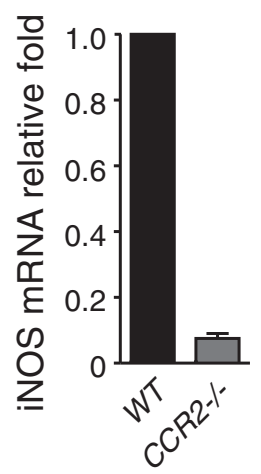

D

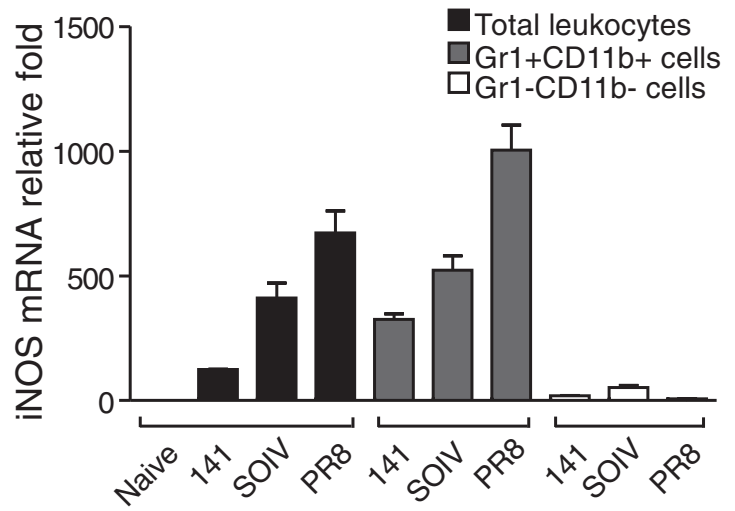

$\mathbf{F}$

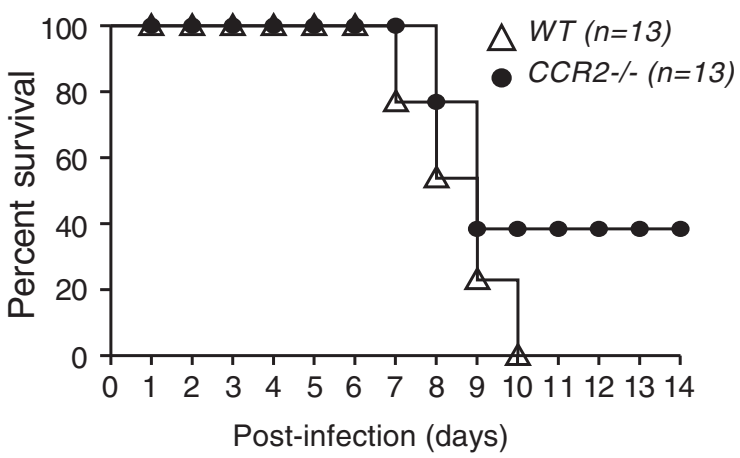

Figure 7 Decreasing pathological effects in PR8-infected CCR2-/- mice. (A) Total leukocytes were harvested from the lungs and counted by trypan blue exclusion. These data are a composite of three independent experiments ( $n=9$ mice per group, mean \pm SEM; ***P < 0.001). (B) Pooled BALFs were subjected to cytokine or chemokine expression analysis using cytokine protein arrays ( $\mathrm{n}=6 \mathrm{mice}$ per group). (C) Relative expression of CCL2, CCL7 and CCL12 was measured by RT-QPCR. The mRNA relative folds were determined by normalizing the level of each group to the corresponding GADPH level and then to total leukocytes from WT mice (mean \pm SEM). This is a representative result from two repeated experiments. (D) RNAs were extracted from total leukocytes, Gr1+ CD11b+ sorted cells and Gr1-CD11b-sorted cells from the virus-infected mice indicated. Relative expression of iNOS transcripts was measured by RT-QPCR. The mRNA relative folds were determined by normalizing the level of each group to the corresponding GAPDH level and then to total leukocytes from naïve mice $(\mathrm{mean} \pm \mathrm{SEM}$ ). Experiment ( $\mathrm{n}=3-6$ mice per group) was performed twice and one representative is shown. (E) RNAs were harvested from leukocytes isolated from the lungs of WT and CCR2-I- infected mice. Relative expression of iNOS was measured by RT-QPCR. The mRNA relative folds were determined by normalizing the level of each group to the corresponding GAPDH level and then to total leukocytes from WT mice ( $\mathrm{n}=3$ mice per group; mean \pm SEM). Experiment was performed twice and one representative is shown. $(\mathbf{F})$ WT $(n=13)$ and CCR2-/- mice $(n=13)$ were infected with PR8 viruses. Survival rate was monitored daily until day 14 post-infection. These data are a composite of three independent experiments. 


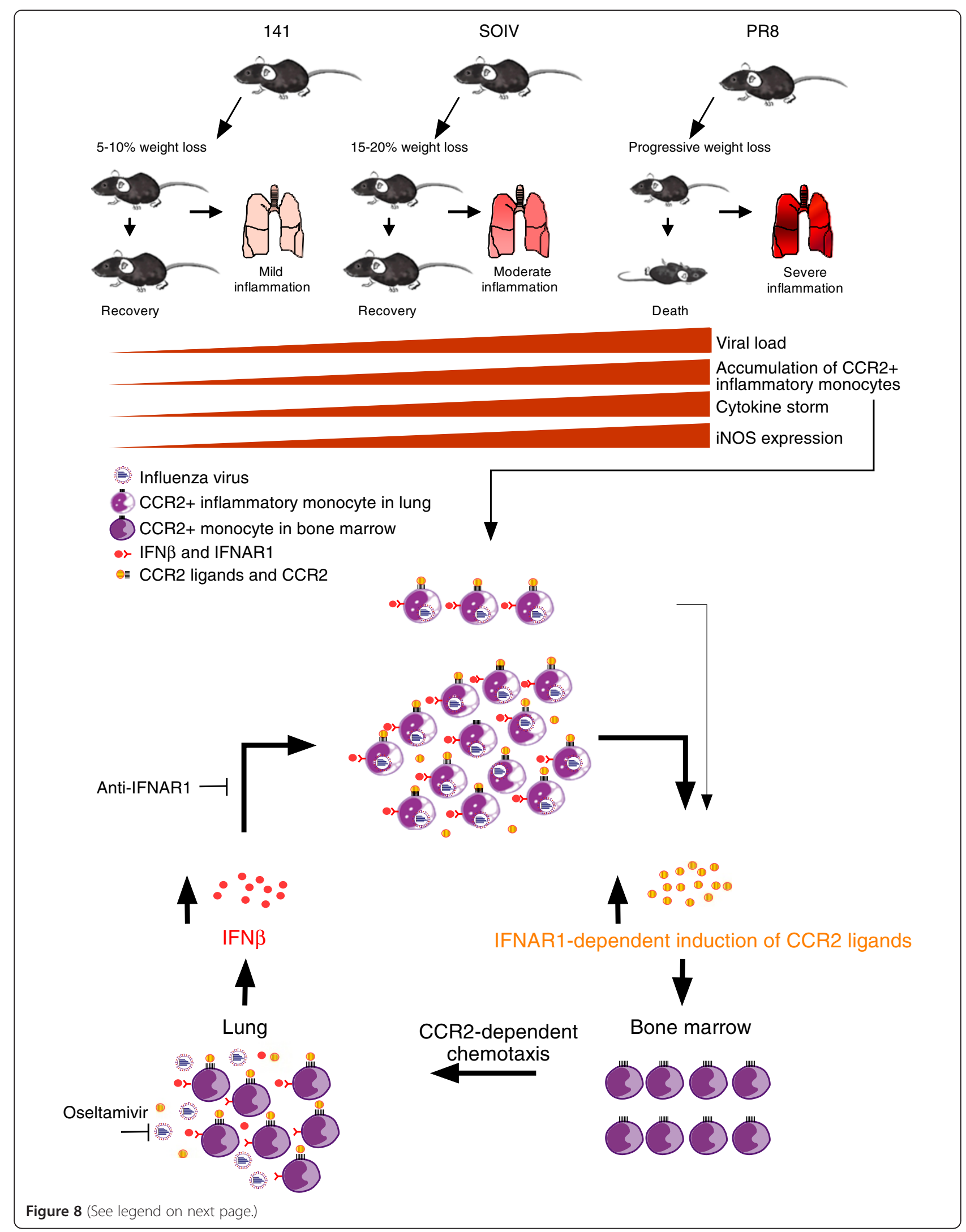


(See figure on previous page.)

Figure 8 Roles of CCR2+ inflammatory monocytes in highly pathogenic IAV infection. We achieved varying degrees of weight loss with mildly, moderately or severely inflamed lungs in mice inoculated with the 141, SOIV or PR8 strains. These H1N1 infection models with variable efficiencies of viral clearance result in the accumulation of varying numbers of CCR2+ inflammatrory monocytes, which are highly associated with the generation of a cytokine storm and expression of iNOS. In the early phase of infection, we propose that a small number of infiltratng CCR2+ inflammatory monocytes are infected with IAV and respond to autocrine and/or paracrine IFN $\beta$, which induces the expression of the CCR2 ligands, CCL2, CCL7 and CCL12. Recruited CCR2+ inflammatory monocytes drive further recruitment of CCR2+ inflammatory monocytes from the BM to the lung through CCR2-dependent chemotaxis. In the late phase of infection, impaired clearance of PR8 virus leads to spread of infection to recently arrived CCR2+ inflammatory monocytes and to sustained production of the IFNAR1-IFN $\beta$ signaling axis-induced CCR2 ligands, which cause infiltrating CCR2+ inflammatrory monocytes to amplify their own recruitment continuously through the IFNAR1-dependent chemokine feedback loop.

type I IFN, which upregulates the levels of MAD5, RIG-I and IRF7 [26,27]. In addition, these IFN-stimulated molecules coupled with viral nucleic acids are responsible for amplified production of type I IFN [28]. Our findings revealed that the rate of virus clearance determines the duration of IFN $\beta$ expression in infiltrating Gr1 + CD11b + cells. Sustained expression of IFN $\beta$ was critical for aggressive recruitment of CCR2+ inflammatory monocytes in severe inflammation. When virus replication was suppressed by Oseltamivir, body weight and influx of CCR2+ inflammatory monocytes were significantly reduced. These results indicated that excessive accumulation of CCR2+ inflammatory monocytes plays a crucial role in the pathological outcomes of highly pathogenic H1N1 IAV infections. Recently, we are continuously threatened by sporadic infections by emerging avian influenza viruses, including highly pathogenic avian $\mathrm{H} 5 \mathrm{~N} 1$ and $\mathrm{H} 7 \mathrm{~N} 9$ viruses which rapidly develop acute respiratory distress syndrome, including excessive infiltration of neutrophils and monocytes into the lungs, high viral loads and hypercytokinemia $[29,30]$. Futhermore, it is worth to see whether the same phenomenon is observed in avain flu infections, such as $\mathrm{H} 5 \mathrm{~N} 1$ and H7N9. If accumulation of CCR2+ inflammatory monocytes is a common phenomenon in highly pathogenic influenza infection, CCR2+ inflammatory monocytes will be a good therapeutic target in infection.

The mechanism of accumulation of CCR2+ inflammatory monocytes in severe IAV infection remains largely unclear. Previous reports have shown that small numbers of neutrophils are recruited early in infection, followed by influx of large numbers of monocytes [4]. Based on our result, CCR2 ligands produced by neutrophils might play a key role in the early recruitment of monocytes. In Figure $1 \mathrm{~F}$, the ratio of neutrophils and monocytes was skewed according to degrees of inflammation at day 7 post-infection. This result indicated two things: (1) Monocyte attractive chemokines were not only provided by neutrophils but also by other inflammatory cells. Using cell sorting, we showed that accumulated CCR2+ inflammatory monocytes are the main contributors of CCR2 ligands and then amplify their own recruitment. (2) Infiltrating monocytes might interfere with the further influx of neutrophils in severe inflammation. A previous study has demonstrated that type I IFN suppresses neutrophil-mediated chemokine attraction, CXCL1 and CXCL2, leading to impaired recruitment of neutrophils [31]. Therefore, we suggested that sustained expression of IFN $\beta$ from CCR2 inflammatory monocytes interrupts the recruitment of neutrophils. Indeed, our data are consistent with previous reports that a doubling of neutrophil numbers is observed in CCR2-/and IFNAR1-/- mice [20,32].

Production of type I IFN is a double edged sword in terms of viral clearance and virus-mediated pathogenesis. Previous studies have shown that prolonged induction of type I IFN was seen in highly virulent IAV infections, leading to severe consequences: (1) Type I IFN-induced apoptosis of alveolar epithelial cells by TRAIL is observed in severe IAV infections [33]. (2) Type I IFN-induced FasL expression in the epithelial cells of the lung contributes to the severity of infection [34]. (3) Type I IFN mediates the development of post-influenza bacterial infections [31]. In our study, CCR2+ inflammatory monocytes amplify their own recruitment by a prolonged IFNAR1-triggered chemokine feedback loop.

In our study, induction of CCR2 ligands in CCR2+ inflammatory monocytes was dependent on the IFNAR1triggered signaling pathway. However, recruitment of CCR2+ inflammatory monocytes could not be completely abolished in IFNAR1-/- mice, suggesting that induction of CCR2 ligands in other cell types by IFNAR1independent pathways may not be excluded. Indeed, expression of CCL2 is regulated by Sphingosine-1phosphate receptor-triggered signaling in pulmonary endothelial cells or by the MyD88-mediated pathway in pulmonary epithelial cells [35-37]. In addition, IL$1 \mathrm{R}$ signaling is also involved in CCL2 induction in undefined cell types during IAV infection [38]. A previous study has demonstrated that mice deficient in a single ligand, either CCL2 or CCL7, only can block 40$50 \%$ monocytes egressing from the BM [39]. Thus, it is not surprising that gene deficiency of CCL2 cannot protect mice against highly pathogenic virus-mediated 
death [7]. Our results indicated that CCL2, CCL7 and CCL12 were highly induced during IAV infections. Therefore, blockage of any single CCR2 ligand is not sufficient to block recruitment of CCR2+ inflammatory monocytes.

Recuirted CCR2+ inflammatory monocytes play a critical role in innate and adaptive immune responses during IAV infections. In successful clearance of 141 and SOIV infecions, CCR2+ inflammatory monocytes expressed high levels of IFN $\gamma R$, MHC class I and MHC class II molecules than those molecules on monocytes isolated from PR8-infected mice (data not shown). Our and previous studies have demonstrated that monocytes are the mainly susceptible cell type to IAV infections [40,41]. Therefore, we suggested that the rate of viral clearance markedly determines the functional direction of inflitrating CCR2+ inflammatory monocytes toward in either protective or pathological role. In infections of MCMV and LCMV, CCR2+ inflammatory monocyte-produced large amount of iNOS and facilitate the production of nitric oxide (NO). NO plays a critical role to impair anti-CD8 T cell responses $[14,15]$. In our study, CCR2+ inflammatory monocytes expressed iNOS; and its expression was correlated with rate of viral clearance. Thus, these results implied that excessive accumulation of CCR2+ inflammatoy monocytes might interfere effective anti-viral CD8 T-cell responses via excessive NO prodution in highly pathogenic IAV infections.

In summary, overabundant innate immune responses produced by monocytes contribute significantly to highly pathogenic virus-mediated fatal outcomes. Based on our findings, the proportion of CCR2+ inflammatory monocytes in the blood and concentration of CCR2 ligands in the serum have potential as translational biomarkers to predict IAV virulence and pathogenesis in an emerging pandemic infection and sporadic infections of avian IAVs. In addition, inhibition of recruitment of CCR2+ inflammatory monocytes or depletion of infiltrating CCR2+ inflammatory monocytes may provide an alternative immunotherapeutic way to reduce the damaging effects of accumulating CCR2+ inflammatory monocytes in highly pathogenic IAV infections.

\section{Conclusion}

The excessive accumulation of Gr1 + CD11b + cells is strongly associated with severe lung pathology in highly pathogenic $1918 \mathrm{H} 1 \mathrm{~N} 1$ and avian H5N1 infections [42]. According to a detailed characterization of $\mathrm{Gr} 1+\mathrm{CD} 11 \mathrm{~b}+$ cells, we found that CCR2+ inflammatory monocytes are a prominent cell type and that they contribute to overabundant inflammatory immune responses. In this study, we demonstrated that the accumulation of infiltrating CCR2+ inflammatory monocytes is determined by the efficiency of host in clearing the virus. Based on our findings, the CCR2+ inflammatory monocytes were one of determinants for pathogenicity of highly pathogenic IAV infection (Figure 8).

\section{Abbreviations \\ IAV: Influenza A virus; IFNAR1: interferon-a/ $\beta$ receptor 1; SOIV: swine-origin influenza virus; MCMV: mouse cytomegalovirus; LCMV: Iymphocytic choriomeningitis virus; BM: bone marrow; NP: nucleoprotein; MLN: mediastinal lymph node; BALF: bronchoalveolar lavage fluid; CFSE: carboxyfluorescein diacetate succinimidyl ester; NO: nitric oxide.}

\section{Competing interests}

The authors declare that they have no competing interests.

\section{Authors' contributions}

SJL designed experiments, performed experiments, analyzed the data and co-wrote the manuscript; ML designed experiments, performed experiments and analyzed the data; RLK provided materials, SRS provided materials; DMO provided materials; JL provided materials; CKL provided materials; HCC provided materials; MYL provided materials; CML provided materials, CNL provided materials and CHT designed experiments and co-wrote the manuscript. All authors read and approved the final manuscript.

\section{Acknowledgments}

We thank Dr. Chen-Kung Chou of Department of Biomedical Science, College of Medicine, Chang Gung University, Taiwan, kindly provided the IVC system for breeding and management of mice. We thank Dr. Tim J. Harrison of UCL Medical School, London, UK, for reviewing the manuscript critically. We thank the Core Instrument Center of Chang Gung University for providing assistance with cell sorting. We thank Dr. Kuo-Feng Weng (Research Center for Emerging Viral Infections, College of Medicine, Chang Gung University, Tao-Yuan, Taiwan) for providing assistance with hypothesis cartoon. This work was supported by National Science Council, Chang Gung Memorial Hospital, National Health Research Institute and Excellent Translational Medicine Research Projects of National Taiwan University College of Medicine and National Taiwan University Hospital (grants: MOST-103-2320-B-182-028-MY3, NSC-102-2325-B-182-002, CMRPD1A0091, CMRPD1A0092 and CMRPD1A0093 to S.-J.L., NSC-1002320-B-002-100-MY3, NHRI-EX102-10031BI and 102 R39012 to C.-H.T; NSC-100-2320-B-182-019-MY3 to R.-L.K.; CMU100-S-03 to H.-C.C).

\section{Author details}

${ }^{1}$ Research Center for Emerging Viral Infections, College of Medicine, Chang Gung University, Tao-Yuan, Taiwan. ${ }^{2}$ Graduate institute of Medical Biotechnology, College of Medicine, Chang Gung University, Tao-Yuan, Taiwan. ${ }^{3}$ Department of Medical Biotechnology and Laboratory Science, College of Medicine, Chang Gung University, Tao-Yuan, Taiwan. ${ }^{4}$ Graduate Institute of Microbiology, College of Medicine, National Taiwan University, Taipei, Taiwan. ${ }^{5}$ Department of Molecular Cell Biology, Health Sciences Research Institute, University of California, Merced, CA, USA. ${ }^{6}$ Genomics Research Center, Academia Sinica, Taipei, Taiwan. ${ }^{7}$ Graduate Institute of Immunology, College of Medicine, National Taiwan University, Taipei, Taiwan. ${ }^{8}$ Graduate Institute of Basic Medical Science, China Medical University, Taichung, Taiwan. ${ }^{9}$ Institute of Microbiology and Immunology, National Yang-Ming University, Taipei, Taiwan. ${ }^{10}$ Department of Laboratory Medicine, Chang Gung Memorial Hospital, Linkou, Taiwan.

Received: 28 July 2014 Accepted: 15 October 2014

Published online: 18 November 2014

\section{References}

1. Graham-Rowe D: Epidemiology: Racing against the flu. Nature 2011, 480:S2-S3.

2. Taubenberger JK, Kash JC: Influenza virus evolution, host adaptation, and pandemic formation. Cell Host Microbe 2010, 7:440-451.

3. Lam TT, Wang J, Shen Y, Zhou B, Duan L, Cheung CL, Ma C, Lycett SJ, Leung CY, Chen X, Li L, Hong W, Chai Y, Zhou L, Liang H, Ou Z, Liu Y, Farooqui A, Kelvin DJ, Poon LL, Smith DK, Pybus OG, Leung GM, Shu Y, Webster RG, Webby RJ, Peiris JS, Rambaut A, Zhu H, Guan Y: The genesis and source of the H7N9 influenza viruses causing human infections in China. Nature 2013, 502:241-244. 
4. Perrone LA, Plowden JK, Garcia-Sastre A, Katz JM, Tumpey TM: H5N1 and 1918 pandemic influenza virus infection results in early and excessive infiltration of macrophages and neutrophils in the lungs of mice. PLOS Pathog 2008, 4:e1000115.

5. Kobasa D, Jones SM, Shinya K, Kash JC, Copps J, Ebihara H, Hatta Y, Kim JH Halfmann P, Hatta M, Feldmann F, Alimonti JB, Fernando L, Li Y, Katze MG, Feldmann $H$, Kawaoka $Y$ : Aberrant innate immune response in lethal infection of macaques with the 1918 influenza virus. Nature 2007, 445:319-323,

6. Baskin CR, Bielefeldt-Ohmann H, Tumpey TM, Sabourin PJ, Long JP, Garcia-Sastre A, Tolnay AE, Albrecht R, Pyles JA, Olson PH, Aicher LD, Rosenzweig ER, Murali-Krishna K, Clark EA, Kotur MS, Fornek JL, Proll S, Palermo RE, Sabourin CL, Katze MG: Early and sustained innate immune response defines pathology and death in nonhuman primates infected by highly pathogenic influenza virus. Proc Natl Acad Sci U S A 2009, 106:3455-3460

7. Salomon R, Hoffmann E, Webster RG: Inhibition of the cytokine response does not protect against lethal H5N1 influenza infection. Proc Natl Acad Sci U S A 2007, 104:12479-12481.

8. Perrone LA, Szretter KJ, Katz JM, Mizgerd JP, Tumpey TM: Mice lacking both TNF and IL-1 receptors exhibit reduced lung inflammation and delay in onset of death following infection with a highly virulent $\mathrm{H} 5 \mathrm{~N} 1$ virus. J Infect Dis 2010, 202:1161-1170.

9. Chen BP, Kuziel WA, Lane TE: Lack of CCR2 results in increased mortality and impaired leukocyte activation and trafficking following infection of the central nervous system with a neurotropic coronavirus. J Immunol 2001, 167:4585-4592

10. Lim JK, Obara CJ, Rivollier A, Pletnev AG, Kelsall BL, Murphy PM: Chemokine receptor $\mathrm{Ccr} 2$ is critical for monocyte accumulation and survival in West Nile virus encephalitis. J Immunol 2011, 186:471-478.

11. Dawson TC, Beck MA, Kuziel WA, Henderson F, Maeda N: Contrasting effects of CCR5 and CCR2 deficiency in the pulmonary inflammatory response to influenza A virus. Am J Pathol 2000, 156:1951-1959.

12. Lin KL, Suzuki Y, Nakano H, Ramsburg E, Gunn MD: CCR2+ monocytederived dendritic cells and exudate macrophages produce influenzainduced pulmonary immune pathology and mortality. J Immuno/ 2008, 180:2562-2572.

13. lijima N, Mattei LM, Iwasaki A: Recruited inflammatory monocytes stimulate antiviral Th1 immunity in infected tissue. Proc Natl Acad Sci U S A 2011, 108:284-289.

14. Daley-Bauer LP, Wynn GM, Mocarski ES: Cytomegalovirus impairs antiviral CD8+ T cell immunity by recruiting inflammatory monocytes. Immunity 2012, 37:122-133.

15. Norris BA, Uebelhoer LS, Nakaya HI, Price AA, Grakoui A, Pulendran B: Chronic but not acute virus infection induces sustained expansion of myeloid suppressor cell numbers that inhibit viral-specific $T$ cell immunity. Immunity 2013, 38:309-321.

16. Kuo RL, Krug RM: Influenza a virus polymerase is an integral component of the CPSF30-NS1A protein complex in infected cells. J Virol 2009, 83:1611-1616.

17. Neumann G, Watanabe T, Ito H, Watanabe S, Goto H, Gao P, Hughes M, Perez DR, Donis R, Hoffmann E, Hobom G, Kawaoka Y: Generation of influenza A viruses entirely from cloned cDNAs. Proc Natl Acad Sci U S A 1999, 96:9345-9350.

18. Manicassamy B, Manicassamy S, Belicha-Villanueva A, Pisanelli G, Pulendran $B$, Garcia-Sastre A: Analysis of in vivo dynamics of influenza virus infection in mice using a GFP reporter virus. Proc Natl Acad Sci U S A 2010, 107:11531-11536.

19. Babcock AA, Toft-Hansen H, Owens T: Signaling through MyD88 regulates leukocyte recruitment after brain injury. J Immunol 2008, 181:6481-6490

20. Seo SU, Kwon HJ, Ko HJ, Byun YH, Seong BL, Uematsu S, Akira S, Kweon MN: Type I interferon signaling regulates Ly6C (hi) monocytes and neutrophils during acute viral pneumonia in mice. PLoS Pathog 2011, 7:e1001304.

21. de Weerd NA, Vivian JP, Nguyen TK, Mangan NE, Gould JA, Braniff SJ, Zaker-Tabrizi L, Fung KY, Forster SC, Beddoe T, Reid HH, Rossjohn J, Hertzog PJ: Structural basis of a unique interferon-beta signaling axis mediated via the receptor IFNAR1. Nat Immunol 2013, 14:901-907.
22. Serbina NV, Pamer EG: Monocyte emigration from bone marrow during bacterial infection requires signals mediated by chemokine receptor CCR2. Nat Immunol 2006, 7:311-317.

23. Tsou CL, Peters W, Si Y, Slaymaker S, Aslanian AM, Weisberg SP, Mack M, Charo IF: Critical roles for CCR2 and MCP-3 in monocyte mobilization from bone marrow and recruitment to inflammatory sites. J Clin Invest 2007, 117:902-909.

24. Karupiah G, Chen JH, Mahalingam S, Nathan CF, MacMicking JD: Rapid interferon gamma-dependent clearance of influenza A virus and protection from consolidating pneumonitis in nitric oxide synthase 2-deficient mice. J Exp Med 1998, 188:1541-1546.

25. Hofmann P, Sprenger H, Kaufmann A, Bender A, Hasse C, Nain M, Gemsa $D$ : Susceptibility of mononuclear phagocytes to influenza $A$ virus infection and possible role in the antiviral response. J Leukoc Biol 1997 61:408-414

26. Hermesh T, Moltedo B, Moran TM, Lopez CB: Antiviral instruction of bone marrow leukocytes during respiratory viral infections. Cell Host Microbe 2010, 7:343-353

27. Honda K, Takaoka A, Taniguchi T: Type I interferon [corrected] gene induction by the interferon regulatory factor family of transcription factors. Immunity 2006, 25:349-360.

28. Gough DJ, Messina NL, Clarke CJ, Johnstone RW, Levy DE: Constitutive type I interferon modulates homeostatic balance through tonic signaling. Immunity 2012, 36:166-174

29. Watanabe T, Kawaoka Y: Pathogenesis of the 1918 pandemic influenza virus. PLOS Pathog 2011, 7:e1001218.

30. Mok CK, Lee HH, Chan MC, Sia SF, Lestra M, Nicholls JM, Zhu H, Guan Y, Peiris JM: Pathogenicity of the novel A/H7N9 influenza virus in mice. MBio 2013, 4:e00362-13.

31. Shahangian A, Chow EK, Tian X, Kang JR, Ghaffari A, Liu SY, Belperio JA, Cheng G, Deng JC: Type I IFNs mediate development of postinfluenza bacterial pneumonia in mice. J Clin Invest 2009, 119:1910-1920

32. Wareing MD, Lyon A, Inglis C, Giannoni F, Charo I, Sarawar SR: Chemokine regulation of the inflammatory response to a low-dose influenza infection in CCR2-/- mice. J Leukoc Biol 2007, 81:793-801.

33. Hogner K, Wolff T, Pleschka S, Plog S, Gruber AD, Kalinke U, Walmrath HD, Bodner J, Gattenlohner S, Lewe-Schlosser P, Matrosovich M, Seeger W, Lohmeyer J, Herold S: Macrophage-expressed IFN-beta contributes to apoptotic alveolar epithelial cell injury in severe influenza virus pneumonia. PLoS Pathog 2013, 9:e1003188.

34. Fujikura D, Chiba S, Muramatsu D, Kazumata M, Nakayama Y, Kawai T, Akira S, Kida H, Miyazaki T: Type-I interferon is critical for FasL expression on lung cells to determine the severity of influenza. PLoS One 2013, 8:e55321.

35. Teijaro JR, Walsh KB, Cahalan S, Fremgen DM, Roberts E, Scott F, Martinborough $\mathrm{E}$, Peach $\mathrm{R}$, Oldstone MB, Rosen $\mathrm{H}$ : Endothelial cells are central orchestrators of cytokine amplification during influenza virus infection. Cell 2011, 146:980-991.

36. Jia T, Leiner I, Dorothee G, Brandl K, Pamer EG: MyD88 and Type I interferon receptor-mediated chemokine induction and monocyte recruitment during Listeria monocytogenes infection. J Immunol 2009, 183:1271-1278

37. Ioannidis I, McNally B, Willette M, Peeples ME, Chaussabel D, Durbin JE, Ramilo O, Mejias A, Flano E: Plasticity and virus specificity of the airway epithelial cell immune response during respiratory virus infection. J Virol 2012, 86:5422-5436.

38. Teijaro JR, Walsh KB, Rice $S$, Rosen H, Oldstone MB: Mapping the innate signaling cascade essential for cytokine storm during influenza virus infection. Proc Natl Acad Sci U S A 2014, 111:3799-3804.

39. Jia T, Serbina NV, Brandl K, Zhong MX, Leiner IM, Charo IF, Pamer EG: Additive roles for MCP-1 and MCP-3 in CCR2-mediated recruitment of inflammatory monocytes during Listeria monocytogenes infection. J Immunol 2008, 180:6846-6853.

40. Helft J, Manicassamy B, Guermonprez P, Hashimoto D, Silvin A, Agudo J, Brown BD, Schmolke M, Miller JC, Leboeuf M, Leboeuf M, Murphy KM, Garcia-Sastre A, Merad M: Cross-presenting CD103+ dendritic cells are protected from influenza virus infection. J Clin Invest 2012, 122:4037-4047.

41. Pang IK, Pillai PS, Iwasaki A: Efficient influenza A virus replication in the respiratory tract requires signals from TLR7 and RIG-I. Proc Natl Acad Sci U S A 2013, 110:13910-13915. 
42. Long JP, Kotur MS, Stark GV, Warren RL, Kasoji M, Craft JL, Albrecht RA, Garcia-Sastre A, Katze MG, Waters KM, Vasconcelos D, Sabourin PJ, Bresler HS, Sabourin CL: Accumulation of CD11b (+) Gr-1 (+) cells in the lung, blood and bone marrow of mice infected with highly pathogenic H5N1 and H1N1 influenza viruses. Arch Virol 2013, 158:1305-1322.

doi:10.1186/s12929-014-0099-6

Cite this article as: Lin et al: The pathological effects of CCR2+ inflammatory monocytes are amplified by an IFNAR1-triggered chemokine feedback loop in highly pathogenic influenza infection. Journal of Biomedical Science 2014 21:99.

\section{Submit your next manuscript to BioMed Central and take full advantage of:}

- Convenient online submission

- Thorough peer review

- No space constraints or color figure charges

- Immediate publication on acceptance

- Inclusion in PubMed, CAS, Scopus and Google Scholar

- Research which is freely available for redistribution 